\title{
Prognostic role of lymphocyte-to-monocyte ratio in pancreatic neuroendocrine neoplasms
}

\author{
Wentao Zhou ${ }^{1,2, *}$, Tiantao Kuang ${ }^{1, *}$, Xu Han ${ }^{2, *}$, Wenqi Chen², Xuefeng Xu ${ }^{1}$, Wenhui Lou ${ }^{2}$ and Dansong Wang1 \\ ${ }^{1}$ The Research Institution of General Surgery, Zhongshan Hospital, Fudan University, Shanghai, China \\ 2Department of Pancreatic Surgery, Zhongshan Hospital, Fudan University, Shanghai, China
}

Correspondence should be addressed to W Lou or D Wang: lou.wenhui@zs-hospital.sh.cn or wang.dansong@outlook.com

*(W Zhou, T Kuang and X Han contributed equally to this work)

\begin{abstract}
Objectives: Systemic inflammation markers have been demonstrated to be associated with prognosis in various tumors. In this study, we aimed to assess the value of neutrophil-to-lymphocyte ratio (NLR), platelet-to-lymphocyte ratio, lymphocyteto-monocyte ratio (LMR), systemic immune-inflammation index and the counts of lymphocyte, monocyte and neutrophil in predicting prognosis among patients with resected pancreatic neuroendocrine neoplasms (pNENs).

Methods: A total of 174 patients were included in the study. Univariate and multivariate analyses were performed to evaluate the predictive roles of inflammation markers for relapse-free survival (RFS) and overall survival (OS) in pNEN patients.

Results: The optimal cut-off values of NLR, LMR and lymphocyte count were 1.9, 5.0 and $1.4 \times 10^{9} / \mathrm{L}$, respectively, determined by the X-tile software. RFS was found to be significantly longer in patients with NLR $\leq 1.9(P=0.041), \operatorname{LMR}>5.0(P<0.001)$ and lymphocyte count $>1.4 \times 10^{9} / \mathrm{L}(P=0.002)$ in comparison to those with NLR $>1.9$, LMR $\leq 5.0$ and lymphocyte count $\leq 1.4 \times 10^{9} / \mathrm{L}$, respectively. Multivariate analysis revealed that LMR (hazard ratio $0.30,95 \% \mathrm{Cl} 0.11-0.85, P=0.023$ ) was an independent predictor for RFS, but not NLR or lymphocyte count. For long-term survival analysis, patients with NLR $\leq 1.9(P=0.016)$ were found to be associated with favorable OS, but NLR was not an independent factor validated by multivariate analysis.

Conclusions: Preoperative LMR is an independent systemic inflammation marker to predict relapses in pNEN patients who underwent curative resections, whose clinical value needs to be verified in further large sample-based prospective studies.

\author{
Key Words \\ - pancreatic neuroendocrine \\ neoplasm \\ - systemic inflammation \\ marker \\ - lymphocyte-to-monocyte \\ ratio
}

- prognosis

Endocrine Connections (2020) 9, 289-298
\end{abstract}

\section{Introduction}

Pancreatic neuroendocrine neoplasm (pNEN) is a rare malignancy arising from pancreatic islet cells and accounts for $1-2 \%$ of all pancreatic tumors (1). However, with the popularization of abdominal imaging and the promotion of endoscopic ultrasonography, the detection rate of pNEN has increased 4.8-fold and 1.2-fold in the United States and Japan in recent years, respectively $(2,3)$. PNENs are a highly heterogenous entity, appearing as various clinical manifestations, histological features and biological behaviors. The long-term prognosis of pNEN is much better than pancreatic adenocarcinomas with a 5-year survival rate ranging from $60 \%$ to $90 \%$ (4). Nevertheless, a certain portion of pNEN patients could advance rapidly even after radical resections. Though several parameters, such as lymph node metastasis, vascular invasion and tumor grade, have been demonstrated to be important prognostic predictors, these markers could be only assessed postoperatively (5). Limited reliable indicators have been

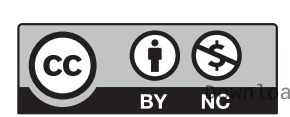

This work is licensed under a Creative Commons Attribution-NonCommercial 4.0 International License. ded from Bioscientifica.com at 04/26/2023 01:13:45PM 
developed to assist in risk stratification and surveillance strategy making for resected patients preoperatively.

Inflammation is a well-known promoter for oncogenesis and progression, and peripheral blood cells could reflect the regional inflammatory responses in tumor microenvironment. Quite a few studies proved that preoperative systemic inflammation markers, such as neutrophil-to-lymphocyte ratio (NLR) and platelet-tolymphocyte ratio (PLR), were associated with relapse-free survival (RFS) and overall survival (OS) in patients with resected digestive system malignancies, including gastric, colorectal, pancreatic and biliary tract cancers $(6,7,8$, $9)$. Recently, some research suggested that inflammation markers could play crucial roles in predicting lymph nodes metastasis, liver metastasis and long-term survival in pNEN patients who underwent surgical resections (10, $11,12)$. However, the cut-off points of these markers varied among different reports and no standard critical value has been defined yet. In addition, few studies set up criteria to exclude easily affected cases, for example, patients with infectious diseases and so on.

In the present study, we aim to evaluate the predictive value of lymphocyte-to-monocyte (LMR), systemic immune-inflammation (SII) index, NLR, PLR and the counts of lymphocyte, monocyte and neutrophil for prognosis among all curatively resected pNEN patients, the first two of which were rarely paid attention to in the previous research. As far as we know, our pNEN cohort is the single largest one to explore the prognostic roles of inflammation markers.

\section{Patients and methods}

Patients with pNENs were searched in the pathological database of Zhongshan Hospital, Fudan University. Those who underwent surgical resections for curative intentions in our hospital from March 2008 to March 2018 were carefully reviewed in the electronic medical record. After excluding patients whose preoperative blood routine tests were unavailable, affected by any infectious diseases within 2 weeks, having history of malignant tumors or combined with hematological disorders, eligible cases were included into final analysis.

Demographic and clinicopathological information was extracted from the medical record. Data regarding platelet count, neutrophil count, lymphocyte count and monocyte count were collected from the blood tests, which were all performed within 10 days before operations. NLR, PLR, LMR and SII were calculated as follows: NLR=neutrophil count/lymphocyte count,
PLR = platelet count/lymphocyte count, LMR=lymphocyte count/monocyte count, and SII=neutrophil count $x$ platelet count/lymphocyte count, respectively. PNENs were graded according to the 2010 World Health Organization (WHO) classification, based on the Ki-67 index and mitotic rate (13). Tumor staging was evaluated according to the TNM system of American Joint Committee on Cancer (AJCC), 8th version (14). Relapse was defined as local recurrence or distant metastasis detected by dynamic enhanced CT or MRI. The primary outcome of this research is relapse-free survival (RFS), which was determined by the interval between the day of operation and the date of relapse or last follow-up. Similarly, overall survival (OS) was defined as the period from the day of operation to the date of death or last follow-up, which was performed on November 20, 2018.

This study was granted by the Ethics Committee of Zhongshan Hospital, Fudan University. Informed consent was obtained from all individual participants included in the study.

\section{Statistical analysis}

Categorical variables were reported as frequencies and percentages. None of the continuous variables were distributed normally in this study, so they were described as medians and interquartile ranges (IQR). The distributions of continuous variables between two or among three independent groups were compared by the Mann-Whitney $U$ test or Kruskal-Wallis test, respectively. Survival curves were plotted using the Kaplan-Meier method and compared by the log-rank test. Multivariate analysis was performed by the Cox proportional hazards model with the forward method (likelihood-ratio test) for variables with $P<0.05$ in the univariate analysis. The optimal cut-off values for prognostic parameters were calculated via the X-tile software (version 3.6.1, Yale University School of Medicine, New Haven, CT, USA). All the other statistical analyses were conducted using the SPSS software (version 25.0, IBM) and GraphPad Prism software (version 7.00, GraphPad Software). A two-side $P$ value of $<0.05$ was considered to be statistically significant.

\section{Results}

\section{Patient characteristics}

A total of 229 patients with pathologically diagnosed pNENs were found in our database, and 174 patients were

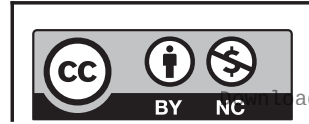

This work is licensed under a Creative Commons Attribution-NonCommercial 4.0 International License. ded from Bioscientifica.com at 04/26/2023 01:13:45PM 
included into final study after ineligible cases were excluded (Supplementary Fig. 1, see section on supplementary materials given at the end of this article). The median follow-up duration was 43.4 months (IQR 24.0-70.0 months). There are 82 males (47.1\%) in the study group and the median age was 53 years (IQR 43-61 years). The vast majority (79.9\%) of the pNENs were nonfunctional, and among the remaining 35 (20.1\%) functional tumors, 32 cases were insulinomas, two were glucagonomas and one was somatostatinoma. The median tumor diameter of the whole cohort was $2.7 \mathrm{~cm}$ (IQR $1.5-4.0 \mathrm{~cm}$ ) and only seven patients $(4.0 \%)$ harbored multiple primary lesions. According to the WHO criteria, 73 cases (42.0\%) were classified as G1, 88 (50.6\%) were G2 and 13 (7.4\%) were G3. Among the entire cohort, nine patients (5.2\%) with liver metastases underwent synchronously curative resections. Detailed characteristics are summarized in Table 1.

\section{Marker selection and cut-off point definition}

Some previous articles reported that the distributions of serum inflammation markers were different between metastatic and non-metastatic tumors (15). Thus, we first evaluated the distributions of NLR, PLR, LMR, SII index, lymphocyte count, monocyte count and neutrophil count between liver metastatic and non-metastatic pNENs, and statistical analysis indicated that none of these markers distributed differently between the two groups (Supplementary Fig. 2). Then, we assessed the values of the markers in predicting RFS among all surgically resected pNEN patients. The results from the X-tile software showed that only NLR, LMR and lymphocyte count could be used as predictive markers for RFS and the optimal cut-off points for them were $1.9,5.0$ and $1.4 \times 10^{9} / \mathrm{L}$, respectively (Supplementary Fig. 3). According to the cutoff values, there were $115(66.1 \%)$ and 59 (33.9\%) patients in NLR $\leq 1.9$ and NLR $>1.9$ groups, 90 (51.7\%) and $84(48.3 \%)$ patients in LMR $\leq 5.0$ and LMR $>5.0$ groups, $30(17.2 \%)$ and $144(82.8 \%)$ patients in lymphocyte count $\leq 1.4 \times 10^{9} / \mathrm{L}$ and lymphocyte count $>1.4 \times 10^{9} / \mathrm{L}$ groups, prespectively (Table 1 ).

\section{Univariate and multivariate analysis of predictive factors for RFS}

Of the whole cohort, 24 patients $(13.8 \%)$ were detected with relapses radiologically, $142(81.6 \%)$ were relapsefree and eight (4.6\%) could not be evaluated, and the 1-, 3 - and 5-year RFS rates were $95.8 \%, 85.4 \%$ and $81.8 \%$.
Cox univariate analysis showed that tumor size $(P<0.001)$, nerve invasion $(P<0.001)$, vascular invasion $(P=0.038)$, lymph node metastases $(P=0.029)$, WHO grade (G2 vs G1, $P=0.005$; G3 vs G1, $P<0.001$ ), TNM stage (II vs I, $P=0.042$; III vs I, $P=0.012$; IV vs I, $P<0.001$ ), synchronous liver metastases $(P<0.001)$, lymphocyte count $>1.4 \times 10^{9} / \mathrm{L}$ $(P=0.003)$, NLR $>1.9(P=0.046)$ and LMR $>5.0(P=0.002)$ were significantly associated with RFS in patients who underwent curative surgery (Table 2). Similarly, KaplanMeier method analysis indicated that NLR $\leq 1.9(P=0.041)$, LMR $>5.0(P<0.001)$ and lymphocyte count $>1.4 \times 10^{9} / \mathrm{L}$ $(P=0.002)$ predicted longer RFS (Fig. 1A, B and C). Further multivariate analysis showed that nerve invasion (hazard ratio (HR) $3.63,95 \% \mathrm{CI} 1.53-8.64, P=0.003$ ), WHO grade (G2 vs G1, HR 4.96, 95\% CI 1.09-22.6, $P=0.038$; G3 vs G1, HR 15.1, 95\% CI 2.87-79.7, $P=0.001$ ), synchronous liver metastases (HR 5.43, 95\% CI 2.17-13.6, $P<0.001$ ) and LMR $>5.0$ (HR 0.30, 95\% CI 0.11-0.85, $P=0.023$ ) were independent factors for RFS, whereas NLR and lymphocyte count were not independent RFS predictors in this pNEN cohort.

Since patients with synchronous liver metastases bore a 5.4-fold risk of postoperative recurrences compared with regional cases, we further evaluated the predictive roles of NLR, LMR and lymphocyte count in the subgroup of non-metastatic pNEN patients. The survival curves still indicated that NLR $\leq 1.9 \quad(P=0.043), \quad$ LMR $>5.0$ $(P=0.007)$ and lymphocyte count $>1.4 \times 10^{9} / \mathrm{L}(P=0.021)$ were significantly associated with better prognosis (Fig. 1D, E and F). In addition, the WHO grade was a widely recognized prognostic factor for pNENs, which was demonstrated again in our cohort (Fig. 2A and Table 2). Further analysis was conducted to assess the value of LMR in predicting RFS in pNEN subgroups classified by the pathological grades. The distributions of LMR were statistically different among these subgroups (Fig. 2B), so the cut-off points of LMR in different grades were determined using the X-tile software again. The ideal cutoff values of LMR for G1, G2 and G3 were 5.0, 4.4 and 3.5 , respectively (Supplementary Fig. 4). Survival analysis manifested that LMR $>4.4$ was associated with favorable prognosis in $\mathrm{G} 2$ patients $(P=0.020)$, but no statistical difference was reached in patients harboring G1 or G3 lesions $(P=0.083 ; P=0.059)$ (Fig. $2 \mathrm{C}, \mathrm{D}$ and $\mathrm{E})$.

\section{Univariate and multivariate analysis of predictive factors for OS}

At the last follow-up, eight (4.6\%) of the pNEN patients already passed away, $152(87.4 \%)$ were still alive and the

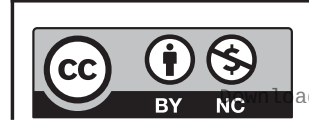

This work is licensed under a Creative Commons Attribution-NonCommercial 4.0 International License. ded from Bioscientifica.com at 04/26/2023 01:13:45PM via free access 
Table 1 Baseline characteristics of pancreatic neuroendocrine neoplasm patients.

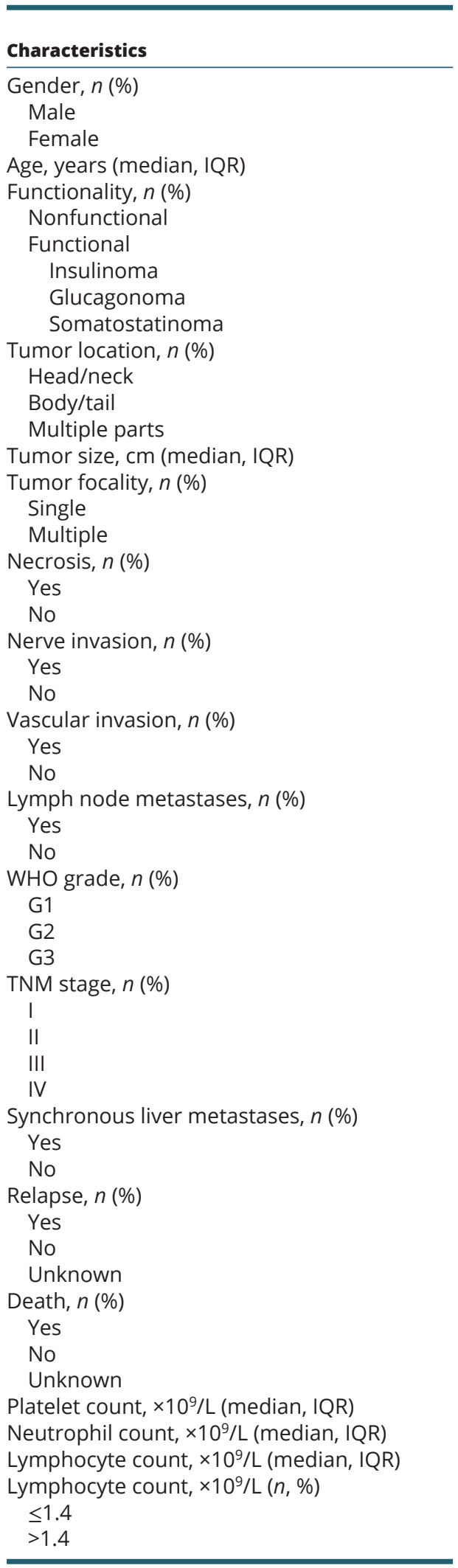

\begin{tabular}{|c|}
\hline $\begin{array}{l}\text { All patients } \\
\quad(n=174)\end{array}$ \\
\hline $\begin{array}{l}82(47.1) \\
92(52.9) \\
53(43-61)\end{array}$ \\
\hline $\begin{array}{c}139(79.9) \\
35(20.1) \\
32(18.4) \\
2(1.1) \\
1(0.6)\end{array}$ \\
\hline $\begin{aligned} 70 & (40.2) \\
103 & (59.2) \\
1 & (0.6) \\
2.7 & (1.5-4.0)\end{aligned}$ \\
\hline $\begin{array}{c}167(96.0) \\
7(4.0)\end{array}$ \\
\hline $\begin{array}{c}8(4.6) \\
166(95.4)\end{array}$ \\
\hline $\begin{array}{r}26(14.9) \\
148(85.1)\end{array}$ \\
\hline $\begin{array}{r}28(16.1) \\
146(83.9)\end{array}$ \\
\hline $\begin{array}{c}15(8.6) \\
159(91.4)\end{array}$ \\
\hline $\begin{array}{l}73(42.0) \\
88(50.6) \\
13(7.4)\end{array}$ \\
\hline $\begin{array}{l}54(31.0) \\
96(55.2) \\
15(8.6) \\
9(5.2)\end{array}$ \\
\hline $\begin{array}{c}9(5.2) \\
165(94.8)\end{array}$ \\
\hline $\begin{array}{c}24(13.8) \\
142(81.6) \\
8(4.6)\end{array}$ \\
\hline $\begin{array}{c}8(4.6) \\
152(87.4) \\
14(8.0)\end{array}$ \\
\hline $\begin{array}{c}205(167-244) \\
3.3(2.5-4.1) \\
1.9(1.6-2.4)\end{array}$ \\
\hline $\begin{array}{r}30(17.2) \\
144(82.8)\end{array}$ \\
\hline
\end{tabular}

(Continued)

https://ec.bioscientifica.com https://doi.org/10.1530/EC-19-0541 (c) 2020 The authors Published by Bioscientifica Ltd
Table 1 Continued.

\begin{tabular}{l} 
Characteristics \\
\hline Monocyte count, $\times 10^{9} / \mathrm{L}$ (median, IQR) \\
Platelet-to-lymphocyte ratio (median, IQR) \\
Neutrophil-to-lymphocyte ratio (median, IQR) \\
Neutrophil-to-lymphocyte ratio, $n(\%)$ \\
$\leq 1.9$ \\
$>1.9$ \\
Lymphocyte-to-monocyte ratio (median, IQR) \\
Lymphocyte-to-monocyte ratio, $n(\%)$ \\
$\leq 5.0$ \\
$>5.0$ \\
Systemic immune-inflammation index \\
(median, IQR)
\end{tabular}

\begin{tabular}{c}
\hline $\begin{array}{c}\text { All patients } \\
(n=174)\end{array}$ \\
\hline $0.38(0.31-0.49)$ \\
$104(89-131)$ \\
$1.6(1.3-2.2)$ \\
$115(66.1)$ \\
$59(33.9)$ \\
$5.0(3.9-6.5)$ \\
$90(51.7)$ \\
$84(48.3)$ \\
$342(241-452)$
\end{tabular}

IQR, interquartile range; WHO, World Health Organization.

remaining $18(8.0 \%)$ could not be contacted. Patients with preoperative NLR $\leq 1.9$ were related to longer OS in comparison to NLR $>1.9$ ones $(P=0.016$ ) (Fig. 3A). However, there was no difference in long-term survival between LMR $\leq 5.0$ and LMR $>5.0$ groups $(P=0.431)$ or between lymphocyte count $\leq 1.4 \times 10^{9} / \mathrm{L}$ and lymphocyte count $>1.4 \times 10^{9} /$ L groups $(P=0.052)$ (Fig. 3B and C). Univariate analysis showed that tumor size $(P=0.002)$, nerve invasion $(P=0.001)$, WHO grade (G3 vs G1, $P=0.007)$ and NLR $>1.9(P=0.032)$ were significantly associated with OS in resected pNEN patients. Nevertheless, only tumor size (HR 1.26, 95\% CI 1.06-1.49, $P=0.008$ ) and nerve invasion (HR $14.5,95 \%$ CI $2.93-72.1, P=0.001)$ were demonstrated as independent factors for OS in this study cohort (Table 3 ).

Tumor size was proven to be an important prognostic parameter for pNEN patients by quite a few reports, but the critical value varied among these studies $(16,17)$. In the present research, our results indicated that $3.6 \mathrm{~cm}$ could be an optimal cut-off point (Supplementary Fig. 5). The 3-, 5- and 7-year survival rates in the tumor size $\leq 3.6 \mathrm{~cm}$ group were $100 \%, 97.9 \%$ and $97.9 \%$ and in the tumor size $>3.6 \mathrm{~cm}$ group were $93.2 \%, 89.9 \%$ and $83.4 \%$, respectively $(P<0.001)$ (Fig. 3D).

\section{Discussion}

Growing evidence has demonstrated the close relationship between inflammation and cancer ever since it was originally proposed by Virchow in 1863 (18). A large number of studies have reported the important effects of inflammation markers in stratifying prognostic risks of patients harboring various kinds of tumors. Recently, Salman et al. (19) found a strong negative correlation between progression-free survival in patients with neuroendocrine tumors and NLR and PLR.

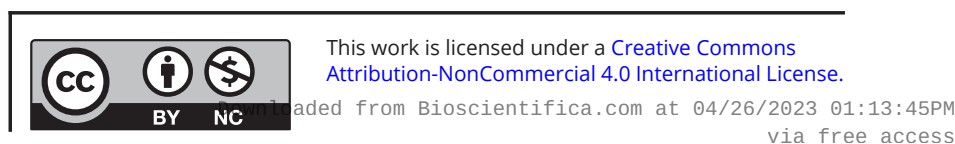


Table 2 Univariate and multivariate analyses for prognostic factors of RFS.

\begin{tabular}{|c|c|c|c|c|}
\hline \multirow[b]{2}{*}{ Characteristics } & \multicolumn{2}{|c|}{ Univariate analysis } & \multicolumn{2}{|c|}{ Multivariate analysis } \\
\hline & $\mathrm{HR}(95 \% \mathrm{Cl})$ & $P$ & $\mathrm{HR}(95 \% \mathrm{Cl})$ & $P$ \\
\hline \multicolumn{5}{|l|}{ Gender } \\
\hline \multicolumn{5}{|l|}{ Male (Ref) } \\
\hline Female & $1.17(0.52-2.59)$ & 0.709 & & \\
\hline Age, years (continuous) & $0.99(0.96-1.02)$ & 0.663 & & \\
\hline \multicolumn{5}{|l|}{ Functionality } \\
\hline \multicolumn{5}{|l|}{ Nonfunctional (Ref) } \\
\hline Functional & $0.14(0.02-1.02)$ & 0.052 & & \\
\hline \multicolumn{5}{|l|}{ Tumor location } \\
\hline \multicolumn{5}{|l|}{ Head/neck (Ref) } \\
\hline Body/tail & $2.00(0.83-4.84)$ & 0.122 & & \\
\hline Multiple parts & - & 0.985 & & \\
\hline Tumor size, cm (continuous) & $1.30(1.14-1.48)$ & $<0.001$ & & NS \\
\hline \multicolumn{5}{|l|}{ Tumor focality } \\
\hline \multicolumn{5}{|l|}{ Single (Ref) } \\
\hline Multiple & $0.93(0.13-6.89)$ & 0.942 & & \\
\hline \multicolumn{5}{|l|}{ Necrosis } \\
\hline \multicolumn{5}{|l|}{ No (Ref) } \\
\hline Yes & $2.45(0.58-10.4)$ & 0.226 & & \\
\hline \multicolumn{5}{|l|}{ Nerve invasion } \\
\hline \multicolumn{5}{|l|}{ No (Ref) } \\
\hline Yes & $5.44(2.36-12.6)$ & $<0.001$ & $3.63(1.53-8.64)$ & 0.003 \\
\hline \multicolumn{5}{|l|}{ Vascular invasion } \\
\hline \multicolumn{5}{|l|}{ No (Ref) } \\
\hline Yes & $2.55(1.06-6.17)$ & 0.038 & & NS \\
\hline \multicolumn{5}{|l|}{ Lymph node metastases } \\
\hline \multicolumn{5}{|l|}{ No (Ref) } \\
\hline Yes & $3.02(1.12-8.11)$ & 0.029 & & NS \\
\hline \multicolumn{5}{|l|}{ WHO grade } \\
\hline G1 (Ref) & & & & \\
\hline $\mathrm{G} 2$ & $8.34(1.90-36.5)$ & 0.005 & $4.96(1.09-22.6)$ & 0.038 \\
\hline G3 & $39.9(8.09-197)$ & $<0.001$ & $15.1(2.87-79.7)$ & 0.001 \\
\hline TNM stage & & & & \\
\hline I (Ref) & & & & \\
\hline II & $8.27(1.08-63.6)$ & 0.042 & & NS \\
\hline III & $16.6(1.85-148)$ & 0.012 & & NS \\
\hline IV & $88.4(10.8-724)$ & $<0.001$ & & NS \\
\hline Synchronous liver metastases & & & & \\
\hline No (Ref) & & & & \\
\hline Yes & $13.9(5.67-34.0)$ & $<0.001$ & $5.43(2.17-13.6)$ & $<0.001$ \\
\hline Platelet count, $\times 10^{9} / \mathrm{L}$ (continuous) & $1.00(1.00-1.00)$ & 0.241 & & \\
\hline Neutrophil count, $\times 10^{9} / \mathrm{L}$ (continuous) & $1.20(0.85-1.69)$ & 0.294 & & \\
\hline $\begin{array}{l}\text { Lymphocyte count, } \times 10^{9} / \mathrm{L} \\
\leq 1.4 \text { (Ref) }\end{array}$ & & & & \\
\hline$>1.4$ & $0.28(0.12-0.65)$ & 0.003 & & NS \\
\hline Monocyte count, $\times 10^{9} / L$ (continuous) & $12.7(0.60-267)$ & 0.103 & & \\
\hline PLR (continuous) & $1.01(1.00-1.01)$ & 0.246 & & \\
\hline NLR & & & & \\
\hline$\leq 1.9$ (Ref) & & & & \\
\hline$>1.9$ & $2.26(1.01-5.02)$ & 0.046 & & NS \\
\hline LMR & & & & \\
\hline$\leq 5.0$ (Ref) & & & & \\
\hline$>5.0$ & $0.21(0.08-0.57)$ & 0.002 & $0.30(0.11-0.85)$ & 0.023 \\
\hline SII index (continuous) & $1.00(1.00-1.00)$ & 0.127 & & \\
\hline
\end{tabular}

HR, hazard ratio; LMR, lymphocyte-to-monocyte ratio; NLR, neutrophil-to-lymphocyte ratio; NS, not significant; PLR, platelet-to-lymphocyte ratio; Ref, reference; RFS, relapse-free survival; SII, systemic immune-inflammation; WHO, World Health Organization.

https://ec.bioscientifica.com

https://doi.org/10.1530/EC-19-0541 (c) 2020 The authors Published by Bioscientifica Ltd

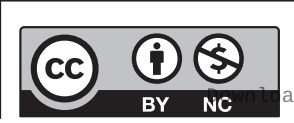

This work is licensed under a Creative Commons Attribution-NonCommercial 4.0 International License. ded from Bioscientifica.com at $04 / 26 / 2023$ 01:13:45PM via free access 
A

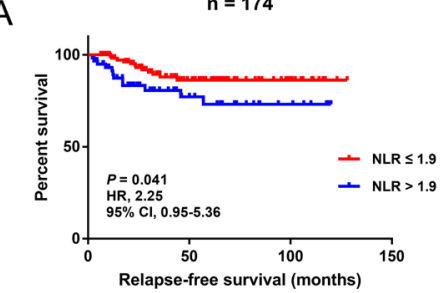

No. at risk
NLR $\leq 1.9$

$\begin{array}{ll}\text { NLR } \leq 1.9 & 115 \\ \text { NLR }>1.9 & 59\end{array}$

D

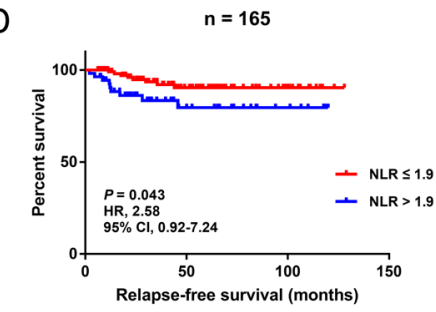

$\begin{array}{lllll}\begin{array}{l}\text { No. at risk } \\ \text { NLR }\end{array} & 111.11 & 49 & 14 & 0\end{array}$
B

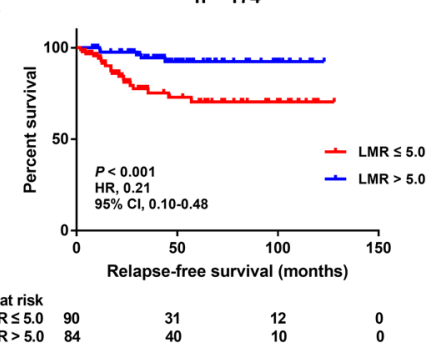

E

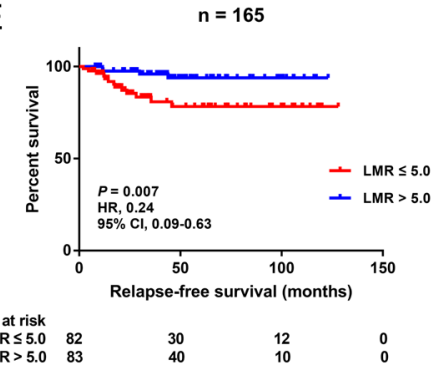

C

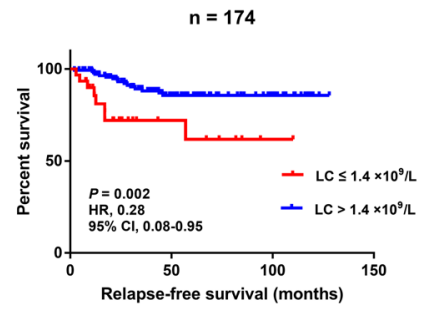

$\begin{array}{rllll}\text { No. at risk } & & & & \\ \text { LC } \leq 1.4 & 30 & 8 & 2 & 0 \\ \text { LC }>1.4 & 144 & 63 & 20 & 0\end{array}$

F
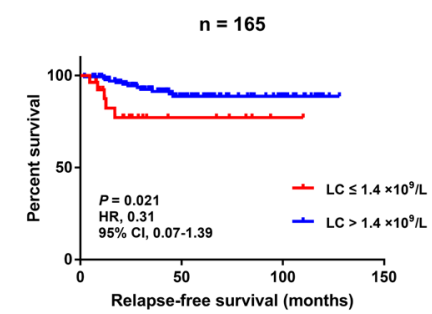

No. at risk
LC $\leq 1.4$

Figure 1

Kaplan-Meier curves for relapse-free survival stratified by NLR (A), LMR (B) and LC (C) in the entire cohort and NLR (D), LMR (E) and LC (F) in the subgroup of non-metastatic patients. NLR, neutrophil-tolymphocyte ratio; LMR, lymphocyte-to-monocyte ratio; LC, lymphocyte count; HR, hazard ratio; Cl, confidence interval.

A

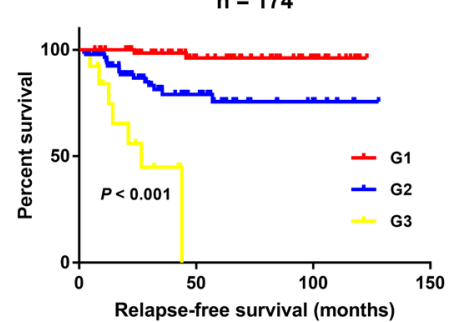

No. at risk

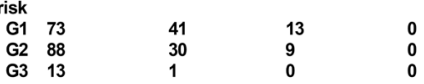

$\mathrm{D}$

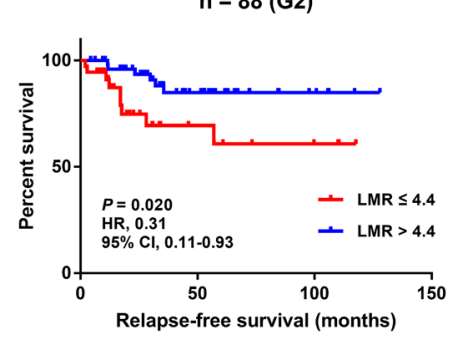

B

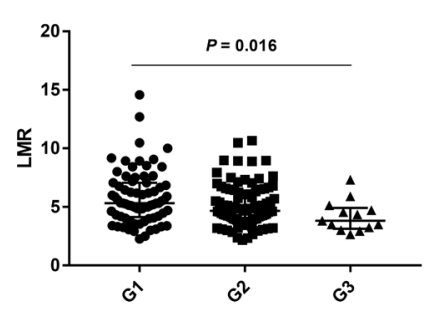

$\mathrm{E}$

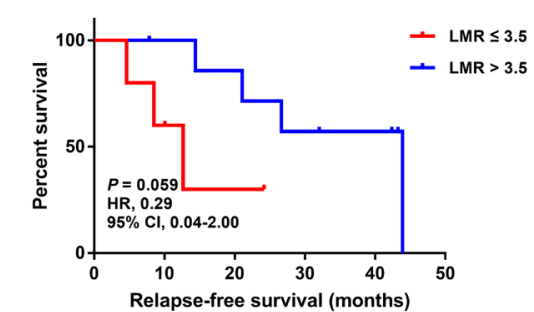

No. at risk

$\begin{array}{lllllll}\text { LMR } \leq 5.0 & 5 & 4 & 2 & 0 & 0 & 0 \\ \text { LMR }>5.0 & 8 & 8 & 7 & 5 & 4 & 0\end{array}$
C

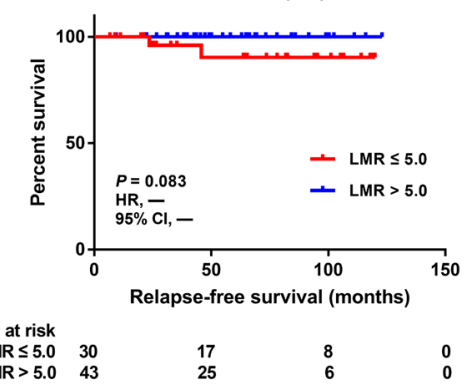

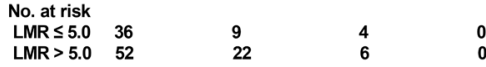

\section{Figure 2}

Subgroup analysis of LMR in pNEN patients graded by WHO criteria. (A) Kaplan-Meier curve for relapse-free survival stratified by tumor grade. (B) Distribution of LMR among patients harboring different tumor grades. Kaplan-Meier curves for relapse-free survival stratified by LMR in the subgroups of G1 (C), G2 (D) and G3 (E) patients. LMR, lymphocyte-to-monocyte ratio; pNEN, pancreatic neuroendocrine neoplasm; WHO, World Health Organization; $\mathrm{HR}$, hazard ratio; $\mathrm{Cl}$, confidence interval.

https://ec.bioscientifica.com https://doi.org/10.1530/EC-19-0541 (c) 2020 The authors Published by Bioscientifica Ltd

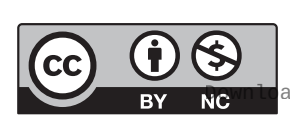

This work is licensed under a Creative Commons Attribution-NonCommercial 4.0 International License. ded from Bioscientifica.com at $04 / 26 / 2023$ 01:13:45PM 
A
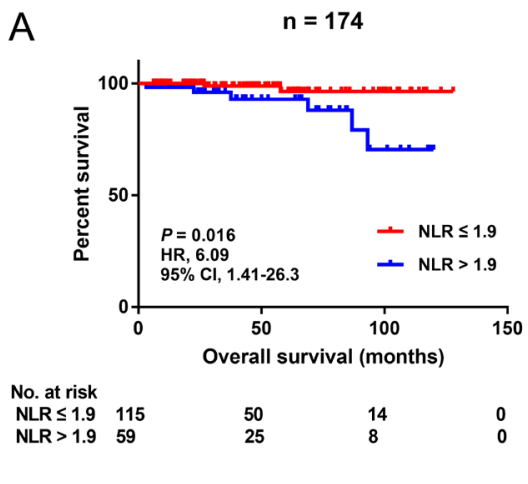

C

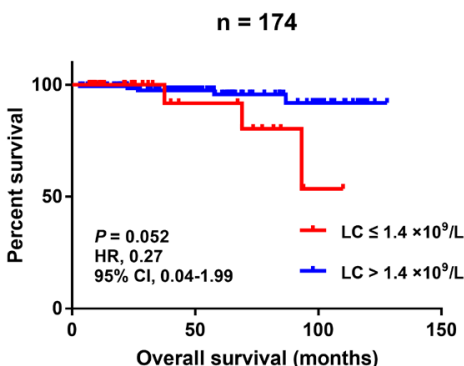

No. at risk

LC $\leq 1.4 \quad 30$

LC $>1.4 \quad 144$

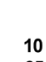

B

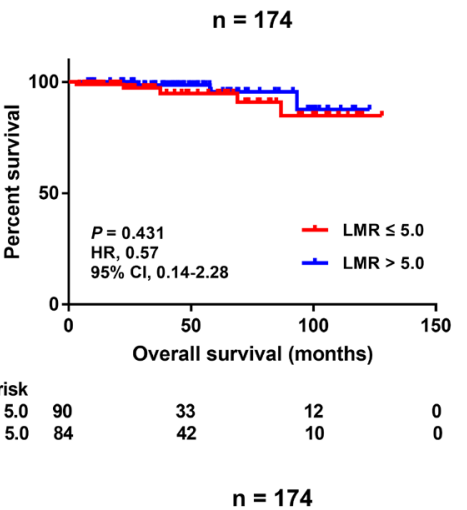

D

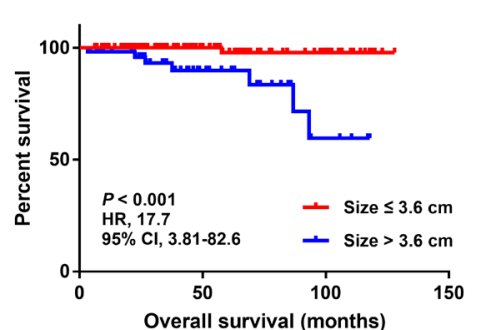

No. at risk Size $\leq 3.6 \mathrm{~cm} \quad 119$ Size $>3.6 \mathrm{~cm} \quad 55$
Similarly, the NLR-based nomogram constructed by Tong et al. (20) displayed a good ability in discriminating lymph node metastasis in pNEN patients. All the previously mentioned work suggested that systemic inflammation markers derived from routine laboratory tests could be used as a reliable and easily obtained tool to predict the prognosis of patients with pancreatic neuroendocrine neoplasms, which could be beneficial to preoperative treatment regimen selection and postoperative follow-up strategy marking.

In the present research, we tested the predictive value of NLR, PLR, LMR and SII index and lymphocyte, monocyte and neutrophil counts for RFS and OS in the curative resected pNEN patients. For relapse, NLR, LMR and lymphocyte count were demonstrated to be significantly associated with RFS by univariate analysis, but only LMR was validated as an independent predictor by multivariate analysis. In addition, LMR was still proven to be a valid RFS indictor in the subgroups of non-metastatic and G2 patients, but not in G1 or G3 cases, which might be impacted by the limited number of outcome events or overall cases in the latter two subgroups, respectively. Since the prognostic role of LMR was first discovered in hematologic malignancies, an increasing number of articles have reported the remarkable value of LMR in predicting prognosis among patients with solid tumors, such as pancreatic and colorectal cancer (21, 22, 23). However, the vast majority of previous pNEN reports only focused on NLR and PLR, and LMR was 'ignored' to some extent. Our study indicated that LMR was a superior systemic inflammation marker in predicting relapses among pNEN patients undergoing surgical resections. Most recently, a prospective analysis performed by Gaitanidis et al. (24) also indicated that LMR was the only independent predictor for RFS in completely resected pNEN patients. However, the cut-off point of LMR was 3.46 in their study, which was quite different from that in ours. This probably could be explained by the fact that the component proportion ratio of G1/G2/G3 cases varied greatly in the two studies, which was proven to be significantly associated with the value of LMR by us. In addition, only 34 surgical cases were included in their analysis, and the optimal cut-off value should be explored in larger prospective cohorts in the future. For longterm survival, there was a statistical correlation between NLR and OS. However, it was not an independent predictor, and no association between LMR and OS was found, either.

The exact mechanism regarding the close relation between decreased LMR and early relapses of pNEN patients largely remains unknown. Lymphocyte is the central component of cellular and humoral immunity, which is critical to immunological surveillance and antitumor immune response. A low lymphocyte status usually means that the existing immune system may not exert antitumor effects completely.
This work is licensed under a Creative Commons Attribution-NonCommercial 4.0 International License. ded from Bioscientifica.com at 04/26/2023 01:13:45PM 
Table 3 Univariate and multivariate analyses for prognostic factors of OS

\begin{tabular}{|c|c|c|c|c|}
\hline \multirow[b]{2}{*}{ Characteristics } & \multicolumn{2}{|c|}{ Univariate analysis } & \multicolumn{2}{|c|}{ Multivariate analysis } \\
\hline & $\mathrm{HR}(95 \% \mathrm{Cl})$ & $P$ & $\mathrm{HR}(95 \% \mathrm{Cl})$ & $P$ \\
\hline \multicolumn{5}{|l|}{ Gender } \\
\hline \multicolumn{5}{|l|}{ Male (Ref) } \\
\hline Female & $1.83(0.43-7.75)$ & 0.414 & & \\
\hline Age, years (continuous) & $1.02(0.97-1.07)$ & 0.481 & & \\
\hline \multicolumn{5}{|l|}{ Functionality } \\
\hline \multicolumn{5}{|l|}{ Nonfunctional (Ref) } \\
\hline Functional & $0.03(0.00-21.2)$ & 0.292 & & \\
\hline \multicolumn{5}{|l|}{ Tumor location } \\
\hline \multicolumn{5}{|l|}{ Head/neck (Ref) } \\
\hline Body/tail & $2.66(0.54-13.2)$ & 0.232 & & \\
\hline Multiple parts & - & 0.991 & & \\
\hline Tumor size, cm (continuous) & $1.25(1.09-1.44)$ & 0.002 & $1.26(1.06-1.49)$ & 0.008 \\
\hline \multicolumn{5}{|l|}{ Tumor focality } \\
\hline \multicolumn{5}{|l|}{ Single (Ref) } \\
\hline Multiple & - & 0.700 & & \\
\hline \multicolumn{5}{|l|}{ Necrosis } \\
\hline \multicolumn{5}{|l|}{ No (Ref) } \\
\hline Yes & $4.15(0.48-35.5)$ & 0.194 & & \\
\hline \multicolumn{5}{|l|}{ Nerve invasion } \\
\hline \multicolumn{5}{|l|}{ No (Ref) } \\
\hline Yes & $11.4(2.74-47.3)$ & 0.001 & $14.5(2.93-72.1)$ & 0.001 \\
\hline \multicolumn{5}{|l|}{ Vascular invasion } \\
\hline \multicolumn{5}{|l|}{ No (Ref) } \\
\hline Yes & $4.24(1.00-17.9)$ & 0.050 & & \\
\hline \multicolumn{5}{|l|}{ Lymph node metastases } \\
\hline \multicolumn{5}{|l|}{ No (Ref) } \\
\hline Yes & $3.96(0.79-19.8)$ & 0.094 & & \\
\hline WHO grade & & & & \\
\hline G1 (Ref) & & & & \\
\hline G2 & $6.62(0.77-57.0)$ & 0.085 & & NS \\
\hline G3 & $31.3(2.54-386)$ & 0.007 & & NS \\
\hline TNM stage & & & & \\
\hline I (Ref) & & & & \\
\hline II & - & 0.944 & & \\
\hline III & - & 0.940 & & \\
\hline IV & - & 0.937 & & \\
\hline Synchronous liver metastases & & & & \\
\hline No (Ref) & & & & \\
\hline Yes & $5.86(0.67-51.2)$ & 0.110 & & \\
\hline Platelet count, $\times 10^{9} / \mathrm{L}$ (continuous) & $1.00(0.98-1.01)$ & 0.663 & & \\
\hline Neutrophil count, $\times 10^{9} / \mathrm{L}$ (continuous) & $1.43(0.79-2.58)$ & 0.243 & & \\
\hline Lymphocyte count, $\times 10^{9} / \mathrm{L}$ & & & & \\
\hline$\leq 1.4$ (Ref) & & & & \\
\hline$>1.4$ & $0.27(0.06-1.12)$ & 0.070 & & \\
\hline Monocyte count, $\times 10^{9} / \mathrm{L}$ (continuous) & $14.4(0.06-3264)$ & 0.334 & & \\
\hline PLR (continuous) & $1.01(0.99-1.02)$ & 0.573 & & \\
\hline NLR & & & & \\
\hline$\leq 1.9$ (Ref) & & & & \\
\hline$>1.9$ & $5.76(1.16-28.6)$ & 0.032 & & NS \\
\hline LMR & & & & \\
\hline$\leq 5.0$ (Ref) & & & & \\
\hline$>5.0$ & $0.57(0.13-2.38)$ & 0.566 & & \\
\hline SII index (continuous) & $1.00(1.00-1.00)$ & 0.273 & & \\
\hline
\end{tabular}

HR, hazard ratio; LMR, lymphocyte-to-monocyte ratio; NLR, neutrophil-to-lymphocyte ratio; NS, not significant; OS, overall survival; PLR, platelet-tolymphocyte ratio; Ref, reference; SIl, systemic immune-inflammation; WHO, World Health Organization.

https://ec.bioscientifica.com

https://doi.org/10.1530/EC-19-0541 (c) 2020 The authors Published by Bioscientifica Ltd

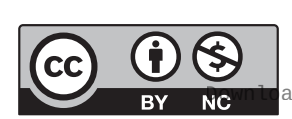

This work is licensed under a Creative Commons Attribution-NonCommercial 4.0 International License. ded from Bioscientifica.com at $04 / 26 / 2023$ 01:13:45PM via free access 
Tumor-infiltrating lymphocytes (TILs), recruited from circulating lymphocytes, have been found to be important tumor suppressors and associate with prognosis in numerous malignancies (25). Recently, Katz et al. (26) reported that decreased TILs count is significantly correlated with poor RFS in patients following resections of neuroendocrine tumors. Similarly, tumor-associated macrophages (TAMs), derived and differentiated from circulating monocytes, play intricate roles in tumor microenvironment. Accumulating data indicated that TAMs could promote tumor progression by supporting tumor cell invasion, facilitating angiogenesis or even weakening immune response, and negative correlation between TAMs density and long-term prognosis was discovered in quite a few cancers as well $(27,28,29)$. Thus, circulating cell-based LMR could be the reflection and amplification of the regional immune and inflammation states in tumor microenvironment.

There are some limitations to be mentioned. First, just as many other retrospective studies, certain selection bias could not be evitable, and well-designed prospective research with large sample sizes needs to be performed. Moreover, since the analysis was conducted with our own data, the result should be further validated in multiple centers to determine whether it could be widely used. Additionally, due to the relatively good prognosis of patients and short observation period in the present pNEN cohort, limited endpoint events occurred, which might impact the statistical results to some extent, especially in the subgroup analysis. We will verify the prognostic value of these markers with prolonged follow-up time in the future.

In conclusion, preoperative LMR was an independent predictor for RFS in the pNEN patients who underwent surgical resections for curative intentions, which could be used as a cheap and convenient marker for surgeons to make optimal therapy and surveillance strategies for individuals. Furthermore, it still could be regarded as an ideal indictor for predicting relapses in non-metastatic or G2 patients. However, the utility and cut-off value should be determined in further large prospective cohorts.

\section{Supplementary materials}

This is linked to the online version of the paper at https://doi.org/10.1530/ EC-19-0541.

\section{Declaration of interest}

The authors declare that there is no conflict of interest that could be perceived as prejudicing the impartiality of the research reported.

\section{Funding}

This work was supported by Shanghai Municipal Health Commission (No. 201840190).

\section{Acknowledgements}

The authors thank Dr Ke Chen for her helpful assistance in data collection.

\section{References}

1 Lawrence B, Gustafsson BI, Chan A, Svejda B, Kidd M \& Modlin IM. The epidemiology of gastroenteropancreatic neuroendocrine tumors. Endocrinology and Metabolism Clinics of North America 201140 1-18, vii. (https://doi.org/10.1016/j.ecl.2010.12.005)

2 Yao JC, Hassan M, Phan A, Dagohoy C, Leary C, Mares JE, Abdalla EK, Fleming JB, Vauthey JN, Rashid A, et al. One hundred years after 'carcinoid': epidemiology of and prognostic factors for neuroendocrine tumors in 35,825 cases in the United States. Journal of Clinical Oncology 200826 3063-3072. (https://doi.org/10.1200/ JCO.2007.15.4377)

3 Ito T, Igarashi H, Nakamura K, Sasano H, Okusaka T, Takano K, Komoto I, Tanaka M, Imamura M, Jensen RT, et al. Epidemiological trends of pancreatic and gastrointestinal neuroendocrine tumors in Japan: a nationwide survey analysis. Journal of Gastroenterology 2015 50 58-64. (https://doi.org/10.1007/s00535-014-0934-2)

4 Modlin IM, Lye KD \& Kidd M. A 5-decade analysis of 13,715 carcinoid tumors. Cancer 200397 934-959. (https://doi.org/10.1002/ cncr.11105)

5 Bosch F, Hofmann K, Coenen M, Pratschke S, Thomas M, Knosel T, Bruns CJ, Guba M, Werner J \& Angele MK. Surgical treatment of pNET - experience of a 'high-volume' center. Surgical Oncology 2018 27 409-414. (https://doi.org/10.1016/j.suronc.2018.05.027)

6 Wang SC, Chou JF, Strong VE, Brennan MF, Capanu M \& Coit DG. Pretreatment neutrophil to lymphocyte ratio independently predicts disease-specific survival in resectable gastroesophageal junction and gastric adenocarcinoma. Annals of Surgery 2016263 292-297. (https://doi.org/10.1097/SLA.0000000000001189)

7 Chan JC, Chan DL, Diakos CI, Engel A, Pavlakis N, Gill A \& Clarke SJ. The lymphocyte-to-monocyte ratio is a superior predictor of overall survival in comparison to established biomarkers of resectable colorectal cancer. Annals of Surgery 2017265 539-546. (https://doi.org/10.1097/SLA.0000000000001743)

8 Stotz M, Gerger A, Eisner F, Szkandera J, Loibner H, Ress AL, Kornprat P, AlZoughbi W, Seggewies FS, Lackner C, et al. Increased neutrophil-lymphocyte ratio is a poor prognostic factor in patients with primary operable and inoperable pancreatic cancer. British Journal of Cancer 2013109 416-421. (https://doi.org/10.1038/ bjc.2013.332)

9 McNamara MG, Templeton AJ, Maganti M, Walter T, Horgan AM, McKeever L, Min T, Amir E \& Knox JJ. Neutrophil/lymphocyte ratio as a prognostic factor in biliary tract cancer. European Journal of Cancer 201450 1581-1589. (https://doi.org/10.1016/j. ejca.2014.02.015)

10 Zhou B, Deng J, Chen L \& Zheng S. Preoperative neutrophil-tolymphocyte ratio and tumor-related factors to predict lymph node metastasis in nonfunctioning pancreatic neuroendocrine tumors. Scientific Reports 20177 17506. (https://doi.org/10.1038/s41598-017 17885-y)

11 Arima K, Okabe H, Hashimoto D, Chikamoto A, Nitta H, Higashi T, Kaida T, Yamamura K, Kitano Y, Komohara Y, et al. Neutrophilto-lymphocyte ratio predicts metachronous liver metastasis of pancreatic neuroendocrine tumors. International Journal of Clinical Oncology 201722 734-739. (https://doi.org/10.1007/s10147-0171111-4) 
12 Luo G, Liu C, Cheng H, Jin K, Guo M, Lu Y, Long J, Xu J, Ni Q, Chen J, et al. Neutrophil-lymphocyte ratio predicts survival in pancreatic neuroendocrine tumors. Oncology Letters 201713 2454-2458. (https://doi.org/10.3892/ol.2017.5716)

13 Kloppel G. Classification and pathology of gastroenteropancreatic neuroendocrine neoplasms. Endocrine-Related Cancer 201118 (Supplement 1) S1-S16. (https://doi.org/10.1530/ERC-11-0013)

14 Yang M, Zhang Y, Zeng L, Ke NW, Tan CL, Tian BL, Xiang B \& Liu XB. Survivals of patients with surgically treated and highgrade pancreatic neuroendocrine carcinomas: a comparative study between two American Joint Committee on Cancer 8th tumor-nodemetastasis staging systems. European Journal of Surgical Oncology 2019 45 1054-1060. (https://doi.org/10.1016/j.ejso.2019.01.010)

15 Abu-Shawer O, Abu-Shawer M, Hirmas N, Alhouri A, Massad A, Alsibai B, Sultan H, Hammo H, Souleiman M, Shebli Y, et al. Hematologic markers of distant metastases and poor prognosis in gynecological cancers. BMC Cancer 201919 141. (https://doi. org/10.1186/s12885-019-5326-9)

16 Sallinen V, Haglund C \& Seppanen H. Outcomes of resected nonfunctional pancreatic neuroendocrine tumors: do size and symptoms matter? Surgery 2015158 1556-1563. (https://doi. org/10.1016/j.surg.2015.04.035)

17 Yamamoto Y, Okamura Y, Uemura S, Sugiura T, Ito T, Ashida R, Kato Y, Ohgi K, Yamada M, Sasaki K, et al. Vascularity and tumor size are significant predictors for recurrence after resection of a pancreatic neuroendocrine tumor. Annals of Surgical Oncology 2017 24 2363-2370. (https://doi.org/10.1245/s10434-017-5823-5)

18 Balkwill F \& Mantovani A. Inflammation and cancer: back to Virchow? Lancet 2001357 539-545. (https://doi.org/10.1016/S01406736(00)04046-0)

19 Salman T, Kazaz SN, Varol U, Oflazoglu U, Unek IT, Kucukzeybek Y, Alacacioglu A, Atag E, Semiz HS, Cengiz H, et al. Prognostic value of the pretreatment neutrophil-to-lymphocyte ratio and platelet-tolymphocyte ratio for patients with neuroendocrine tumors: an Izmir Oncology Group study. Chemotherapy 201661 281-286. (https://doi org/10.1159/000445045)

20 Tong Z, Liu L, Zheng Y, Jiang W, Zhao P, Fang W \& Wang W. Predictive value of preoperative peripheral blood neutrophil/ lymphocyte ratio for lymph node metastasis in patients of resectable pancreatic neuroendocrine tumors: a nomogram-based study. World Journal of Surgical Oncology 201715 108. (https://doi.org/10.1186/ s12957-017-1169-5)
21 Li ZM, Huang JJ, Xia Y, Sun J, Huang Y, Wang Y, Zhu YJ, Li YJ, Zhao W, Wei WX, et al. Blood lymphocyte-to-monocyte ratio identifies high-risk patients in diffuse large B-cell lymphoma treated with R-CHOP. PLOS ONE 20127 e41658. (https://doi.org/10.1371/ journal.pone.0041658)

22 Neofytou K, Smyth EC, Giakoustidis A, Khan AZ, Williams R, Cunningham D \& Mudan S. The preoperative lymphocyte-tomonocyte ratio is prognostic of clinical outcomes for patients with liver-only colorectal metastases in the neoadjuvant setting. Annals of Surgical Oncology 201522 4353-4362. (https://doi.org/10.1245/ s10434-015-4481-8)

23 Qi Q, Geng Y, Sun M, Wang P \& Chen Z. Clinical implications of systemic inflammatory response markers as independent prognostic factors for advanced pancreatic cancer. Pancreatology 201515 145-150. (https://doi.org/10.1016/j.pan.2014.12.004)

24 Gaitanidis A, Patel D, Nilubol N, Tirosh A, Sadowski S \& Kebebew E. Markers of systemic inflammatory response are prognostic factors in patients with pancreatic neuroendocrine tumors (PNETs): a prospective analysis. Annals of Surgical Oncology 201825 122-130. (https://doi.org/10.1245/s10434-017-6241-4)

25 Nishijima TF, Muss HB, Shachar SS, Tamura K \& Takamatsu Y. Prognostic value of lymphocyte-to-monocyte ratio in patients with solid tumors: a systematic review and meta-analysis. Cancer Treatment Reviews 201541 971-978. (https://doi.org/10.1016/j. ctrv.2015.10.003)

26 Katz SC, Donkor C, Glasgow K, Pillarisetty VG, Gonen M, Espat NJ, Klimstra DS, D'Angelica MI, Allen PJ, Jarnagin W, et al. T cell infiltrate and outcome following resection of intermediate-grade primary neuroendocrine tumours and liver metastases. HPB 201012 674-683. (https://doi.org/10.1111/j.1477-2574.2010.00231.x)

27 Condeelis J \& Pollard JW. Macrophages: obligate partners for tumor cell migration, invasion, and metastasis. Cell 2006124 263-266. (https://doi.org/10.1016/j.cell.2006.01.007)

28 Chanmee T, Ontong P, Konno K \& Itano N. Tumor-associated macrophages as major players in the tumor microenvironment. Cancers 20146 1670-1690. (https://doi.org/10.3390/ cancers6031670)

29 Steidl C, Lee T, Shah SP, Farinha P, Han G, Nayar T, Delaney A, Jones SJ, Iqbal J, Weisenburger DD, et al. Tumor-associated macrophages and survival in classic Hodgkin's lymphoma. New England Journal of Medicine 2010362 875-885. (https://doi. org/10.1056/NEJMoa0905680)

Received in final form 16 February 2020

Accepted 11 March 2020

Accepted Manuscript published online 11 March 2020 https://ec.bioscientifica.com https://doi.org/10.1530/EC-19-0541 (c) 2020 The authors Published by Bioscientifica Ltd

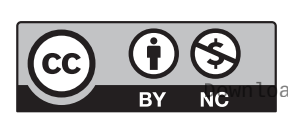

This work is licensed under a Creative Commons Attribution-NonCommercial 4.0 International License. ded from Bioscientifica.com at 04/26/2023 01:13:45PM 